\title{
Developing scientific decision making by structuring and supporting student agency
}

\author{
N. G. Holmes(1) \\ Laboratory of Atomic and Solid State Physics, Cornell University, Ithaca, New York 14853, USA \\ Benjamin Keep \\ Graduate School of Education, Stanford University, Stanford, California 94305, USA \\ Carl E. Wieman \\ Graduate School of Education and Department of Physics, Stanford University, \\ Stanford, California 94305, USA
}

(Received 7 November 2019; accepted 23 December 2019; published 10 February 2020)

\begin{abstract}
Scientific expertise is manifested through extensive cycles of making and acting on decisions. To learn the processes and practices of science, therefore, students must have practice with scientific decision making. We argue that this can only happen if students are afforded agency: the opportunity to make decisions to pursue a goal. In this study, we compared two different introductory physics labs through the lens of structuring and supporting student agency. We explore both the role of decision making agency (students are afforded opportunities to make decisions about their lab investigations) and epistemic agency (students are afforded opportunities to generate knowledge). We found that the two labs differed in both the amount and type of structure provided to students: one lab (the intervention condition), with more overall structure, cued student decision making; the other lab (control condition), with less overall structure, made decisions for students. Students in the intervention condition documented, on average, ten times more decisions during their investigations, including more unprompted decisions. In contrast, in labs with less available epistemic agency (i.e., labs where they had to verify or demonstrate canonical models or constants), students in the intervention condition documented fewer decisions than in labs with more available epistemic agency. We associate the improved decision making with students taking up personal agency, based on significant shifts in students' tone as they described their experimental methods (from passive, third-person narratives to active, first-person narratives). Students in the intervention condition also made higher-quality decisions in line with scientific practice. The study speaks to the important nuances between structure and agency in instructional labs and tests the generalizability of previous research on lab instruction to a two-year college population.
\end{abstract}

DOI: 10.1103/PhysRevPhysEducRes.16.010109

\section{INTRODUCTION}

There are compelling calls for science instruction to focus on developing students' scientific practices [1,2]. Authentic scientific practice, as represented by how scientists approach and solve problems [3], involves making a series of decisions [4]. These decisions are guided by the knowledge and reasoning processes of the discipline [5]; decisions such as: is this an appropriate question?; what data will answer this question?; and what interpretations are supported by the data? In this paper, we evaluate the principle that teaching scientific practices must involve supporting and structuring students' decision making to encourage students to take up

Published by the American Physical Society under the terms of the Creative Commons Attribution 4.0 International license. Further distribution of this work must maintain attribution to the author(s) and the published article's title, journal citation, and DOI. available agency to make decisions during the learning process. We also evaluate whether labs that foster student agency to design parts of the experiments produce similar benefits with a two-year college population as seen in other studies (e.g., Refs. [6,7]).

\section{A. What is agency and what can it provide?}

Definitions for student agency in education research literature are diverse and varied [8,9]. In this work, we build from a definition that an agent is someone who is making decisions to pursue a goal [8-11]. Agency can be contrasted with autonomy, which refers to having the free will to make choices. An agent may or may not be autonomous. An agent can also be contrasted with an actor, who may be carrying out the intention of someone else, with little to no independent decision making. In this way, agency may be considered as sitting between acting and behaving autonomously: "It is not the acting alone that defines agency, but the acting for someone or something 
that is defining" [12] (p. 256). An autonomous agent is acting for themselves, internally motivated in their decision making [13].

Having goal-driven agency can be demonstrated through the decisions one makes: setting goals and planning how to achieve them (planning), carrying out the plan with selfregulation (executing), and reflecting on whether the goals were sufficiently met (reflecting) [9-11]. Moving through these phases with agency is not a strictly linear or straightforward process. One must have the motivation to pursue the goals $[10,14]$, and the time and space to enact the plan [15].

Bandura describes how an individual (or agent) sets standards associated with their goals and, once the initial standards have been met, sets increasingly higher standards for themselves [10]. Thus, the agent must hold a strong sense of efficacy [16] such that they believe that they can achieve these new standards [17]. In instructional contexts, students' motivations, self-efficacy, and environmental constraints may or may not cause them to set these new standards. Thus, instruction should support students to take up this agency and engage in the appropriate self-regulating behaviors to achieve the instructional goals.

The reverse is also true: exercising agency can also develop motivation and self-efficacy. Individual agency encourages individual participation [18], including for those who may not usually participate (such as due to gender, class, or race [19]. In addition, agency during learning creates opportunities for individual learning [20] when each student can manipulate and respond to learning resources [21]. Applying these ideas in practice presents many challenges and open questions [22], particularly because of the complexities with how to situate agency on the spectrum between acting (carrying out the actions) and autonomy (having full control and free will) for optimal learning.

\section{B. Agency and scientific practice}

Learning science involves not just learning the results of science (e.g. concepts) but also the process and practices of science. Scientific practice refers to the activities scientists actually do, and not the systematic set of procedures associated with the term scientific method: "Scientific practice is based not on rules, but on processes of perpetual evaluation and critique that support progress in explaining nature" [5] (p. 1043). Engaging students in scientific practice as perpetual cycles of evaluation and critique means that students must iteratively engage in the extensive decision making associated with a scientific investigation. Scientists must make decisions at many junctures: they must choose a research question, identify the relevant variables and controls, select materials and apparatus, identify analysis methods, design ways to troubleshoot the apparatus, create contingency plans, and much more [4]. These decision-making processes are linked to achieving a goal, such as answering a research question or solving a perplexing problem. Engaging in scientific practices, therefore, relates directly to our definition of agency.

Instructional laboratory activities, where students are working with equipment and data, are prime (though seldom realized) opportunities for teaching scientific practices through decision making. Historically, instructional labs have fallen short of giving students experiences with authentic scientific practice [4,23-25]. In traditional lab courses, students' investigations are highly structured, in that they tell students precisely what to do and what to find. Traditional labs have been shown to negatively shift students' perceptions of experimental physics [26,27] and to provide no measurable benefits for learning the content they aim to verify [28-30].

In this paper, we argue that the impacts of instructional labs can be viewed through the lens of agency. We particularly focus on two forms of agency: decision-making agency and epistemic agency.

\section{Decision-making agency and instructional labs}

We define decision-making agency as the agency students have to make decisions in their investigations. As outlined above, experimenters can decide everything from what equipment to use, how many data points to collect, to how to analyze their data. Traditional labs typically make many of these decisions for students.

Figure 1 is text from a traditional lab used in this study. The bolded statements highlight some of the ways structure limits students' decision-making agency. Throughout the example, students are told exactly what to do and, in many cases, how to do it. In carrying out this lab, students are actors, following a prescribed procedure to replicate a prescribed outcome [4,31].

Decision-making agency could be supported in instructional labs in multiple ways. For example, the decisionmaking process can be scaffolded such that instructions identify what decisions need to be made without telling students what to do or how to do it [32] and require students to reflect on their decisions $[6,30]$. Labs where students designed their own experiments to test hypotheses to explain curious observations [33] were found to be more productive when students were provided with careful scaffolding and explicit reflection opportunities [30]. Scaffolding can effectively come in the form of guidance as to what decisions are needed. Such guidance may remind students about the choices they have or direct students to engage in a particular cognitive activity that maintains an element of agency [34]. Guidance may be directive (for example, telling the students to decide on the number of repeated trials to use) or subtle (for example, hinting that students should find ways to reduce uncertainty, without indicating the use of repeated trials). This structure, therefore, identifies the decisions that are needed and prompts students to make those decisions but with no predefined correct answer. Scaffolding can also support reflective 
- Then use the position data to determine the velocity from point to point. To do this calculate the average velocity: $\Delta x / \Delta t$. Note that the time between data points is not constant and this needs to be taken into account.

- Make a velocity vs. time graph, pick out a 'bounce' and determine the slope by graphing just the data points on that bounce and using a linear fit. Since acceleration is the derivative of velocity, the slope of your graph should be the acceleration due to gravity.

- Do this four times. Take the mean and standard error of your measurements to report a value for $g$.

- Go back to your data table and create a column for acceleration the same way you did for velocity.

- Compare the values in your acceleration column to the one you've found by curve fitting. Comment upon this in your conclusion.

FIG. 1. Example text from a traditional lab. Bolded statement are examples of structure that limits students' decision making agency while italicized statements are examples of structure that limits students' epistemic agency.

decision making [11] by cueing students to self-explain their decisions [34-36] or evaluate the outcomes of a decision (for example, checking whether the measurement uncertainties are smaller than before). With the scaffolding faded over time, students can learn to engage in the reflective decision making on their own [6,37].

Alternatively, structure could be removed entirely so students must make all decisions on their own. In science education, however, the goal is not just for students to make decisions, but for students to learn to make good decisions; that is, following accepted scientific practices. Although definitions of agency may appear to make it antagonist to imposed structure, supporting students to learn to make good decisions inevitably requires some form of structure in the form of support, scaffolding, or guidance [18,38,39]. This necessary structure calls upon the student to practice making the appropriate scientific decisions followed by feedback and opportunities for reflection on those decisions. Thus, as others have argued, we claim that structure is necessary for "enabling" productive scientific agency [39] (p. 4). If one considers having agency as having the capacity to make decisions and act [21], then structure in instruction can support the practice and quality of those decisions. In this paper, we test the claim that student decision making is improved (in both quantity and quality) when lab instructions include structure to support student agency, rather than simply removing structure.

\section{Epistemic agency and instructional labs}

Students can also have the agency to create their own knowledge of the phenomenon based on their investigations. We refer to this type of agency as epistemic agency, although the term can also encompass the entire student process of generating knowledge [40]. Specifically, we use epistemic agency to mean that students are the producers of knowledge through their decisions [41], such that there are no clear right or wrong answers [42]. In the previous example in Fig. 1, italicized statements highlight some of the ways structure limits students' epistemic agency. Students are given the physics theory they should use in their calculations and even the intended outcome of the experiment (their acceleration should equal that due to gravity).

To support epistemic agency, students should have the opportunity to use their investigations to generate knowledge, rather than to verify a canonical concept [43]. One must differentiate freedom to generate any knowledge from freedom to generate knowledge that is supported by evidence [43]. As such, there is likely a relationship between epistemic agency and productive decision-making agency.

In many introductory college physics courses, however, most of the knowledge being investigated is known-either to the students or to the broader scientific community. In fact, many introductory physics students tend to expect that the purpose of lab instruction is to verify or confirm the concepts from lecture [44]. In biology, a new trend has been to transform traditional lab courses into Course-Based Undergraduate Research Experiences (CUREs) [45]. In CUREs, as in authentic research experiences, students' investigations aim to answer research questions whose answers are unknown to scientists. Several recent studies, however, have called to question whether this level of epistemic agency is necessary for the array of benefits associated with CUREs [46,47].

\section{Research questions}

In this study, we had one driving research question: how does structure (in the form of guidance and cues) support students' decision-making agency and epistemic agency, in terms of the quality and quantity of students' decisions in scientific investigations? This question includes three subquestions:

(1) How does the quantity of students' decision making vary based on the structure provided to them: either through decisions made for them, decision making cued, or decisions left open? How does the quantity of students' decision making evolve over time?

(2) How does the quantity of students' decision making vary based on the epistemic agency afforded in the lab activity, particularly comparing labs that aim to confirm known results (verification labs with low available epistemic agency) with labs that aim to answer a question with multiple, possible, unknown 
outcomes (evaluation labs with high available epistemic agency)?

(3) How does the quality of students' decision making vary based on their decision making agency and the associated structure? Here we focus on two specific measures of quality: whether students decide to check results (whether conflicting or expected) and whether students' conclusions are supported by their evidence.

We ultimately want to probe the balance between structure and agency that results in students making good decisions and learning scientific practice. We probe not just the amount of structure but also the type of structure: instructions may make decisions for students; cue students to make decisions; or not mention a decision. The latter case requires students to identify that a decision is needed. We also want to explore the interactions between structure, decision making agency, and epistemic agency. As mentioned above, students may have the support to make decisions about how to investigate a phenomenon, but this agency may be hampered when they are verifying a phenomenon they already know (low epistemic agency). Finally, we distinguish the quality and quantity of students' decision making; Making a variety of decisions during an experiment does not necessitate making good decisions. Throughout, we also note any changes over time, recognizing that any such effects are not clearly distinguishable from the effects of structure, decision making agency, and epistemic agency.

\section{METHODS}

To answer our research questions, we compared student work from multiple sections of an introductory physics lab course carried out over two academic terms at a two-year college. Between the two terms, the type of instruction in the corresponding lecture course was unchanged and the lab course used the same physics lab activities (i.e., same experimental equipment and context). The instructions provided to the students were changed in the experimental sections, manipulating the structure provided and agency available to the students. Both courses involved activities with either high or low available epistemic agency (that is, evaluation and verification activities, as defined above), allowing us to evaluate some interplay between structure, decision making agency, and epistemic agency.

\section{A. Participants}

Participants were students enrolled in an introductory, calculus-based physics course at a two-year college during the 2015-2016 academic year. At the community college, $53 \%$ of the student population identify as female and $46 \%$ as male, the average age is 26 , and the self-identified ethnicities of the student population are 31\% White, 26\%-30\% Asian, 22\%-25\% Latino/a, 6\% Filipino, 5\% African American, and $2 \%$ Native American or Pacific Islander $[48,49]$.
The course enrolled approximately 60 students each term. Students enrolled in one of multiple weekly threehour lab sections, with between 15 and 30 students in each section. Students worked in groups of two to four. Students were free to switch groups from week to week, but most groups remained quite consistent throughout the term. The number of students in each group, however, fluctuated in individual weeks as individual group members were absent. The groups in the control condition tended to be smaller (groups of 2 or 3 ) than in the intervention condition (groups of 3 or 4$)$.

Each group summarized their investigations by handwriting lab narratives on blank pieces of paper (one collaborative narrative per group), which they submitted by the end of the lab period to be graded by the instructor. They received their graded narratives at the start of the subsequent lab session. All sections were provided similar instruction about the types of information that should be recorded in the lab narratives (namely, detailed information about what they did and found throughout the lab period). Students were not provided with grading rubrics in advance.

\section{B. Instructional conditions}

The study compared two conditions, with a number of features common to both (Table I). Both conditions had nine lab sessions spread across the 12-week term with one lab experiment per session. Each lab session was three hours in duration. One faculty instructor (instructor A) taught only control sections during both terms, and the second instruction (instructor B) taught a control section in the fall term and two intervention sections in the winter term. The faculty instructors also taught the lecture portion of the course.

The physical phenomena being investigated did not differ between conditions, though the order of the labs throughout the term varied slightly (Fig. 2) to accommodate different learning goals between conditions (described below). Students were given an experimental question or topic to investigate involving either verification of a particular outcome (verification activities) or investigation of a phenomenon with no intended outcome specified (evaluation activities). These two types of activities (verification or evaluation) represent varied amounts of available epistemic agency in both conditions (low and high, respectively). Both labs involved a mix of verification and evaluation activities. The labs in both conditions aimed to teach students scientific practices such as uncertainty and data analysis. The structure of the activities differed significantly between conditions.

In the control condition, the lab activities were also designed to demonstrate material from the lecture portion of the course, a relatively traditional goal of physics lab courses. Students were given a target topic and investigative goal (for example, to measure the acceleration due to gravity using an Atwood's machine), as well as a theoretical description of the phenomenon. Students were 
TABLE I. Similarities and differences between conditions. There were also many differences in the written lab instructions, which are contrasted as part of the study.

\begin{tabular}{|c|c|c|}
\hline & Control & Intervention \\
\hline Learning objectives & $\begin{array}{l}\text { Uncertainty, data analysis skills, } \\
\text { and conceptual physics }\end{array}$ & $\begin{array}{l}\text { Uncertainty, data analysis, } \\
\text { and critical thinking skills }\end{array}$ \\
\hline Student products & $\begin{array}{l}\text { Written lab narratives, submitted } \\
\text { by the end of the lab session }\end{array}$ & $\begin{array}{l}\text { Written lab narratives, submitted } \\
\text { by the end of the lab session }\end{array}$ \\
\hline Time per lab & Three hours & Three hours \\
\hline Number of groups (students) & $30(\approx 65)$ & $20(\approx 60)$ \\
\hline Instructors & $\mathrm{A}$ and $\mathrm{B}$ & $\mathrm{B}$ \\
\hline
\end{tabular}

usually given a prescribed protocol to follow to reach the intended goal, typically to confirm the theory. This included instructions about how to set up the equipment, how much data to collect, and how to analyze those data to obtain the intended result. Two control lab activities did not specify the target outcome. In these labs, students were instructed how to collect data, and those data were used to determine the outcome (evaluation labs with higher epistemic agency). Approximately 65 students were in the control condition (the number fluctuated between sessions due to variations in attendance).

In the intervention condition, the lab activities explicitly did not aim to reinforce learning of the lecture material. The instruction was adapted from a lab framework that uses comparing, evaluating, and iterating to improve students' critical thinking skills [6]. In these labs, students were given an investigative goal (for example, to evaluate the acceleration due to gravity using an Atwood's machine, as in the control condition). The instructions, however, provided little to no information about the relevant theory or the experimental protocol. Instead, the instructions included guiding cues or questions that were intended to support students in designing, carrying out, and evaluating the investigation. Cues included telling students to make particular comparisons between data and models, reflect on those comparisons, and design ways to improve their measurements or investigations. Approximately 60 students were in the intervention condition (again, the number fluctuated between sessions due to variations in attendance).

The materials for the intervention condition were developed by one of the researchers and one of the course instructors. The two individuals met several times during the first term of the study (with only the control condition labs) to adapt the existing control labs to the new framework. Statements from the instructions in the control condition were often replaced by questions in the lab instructions for the intervention condition. For example, instructions in the control condition would tell students to "collect data for seven or eight measurements." This was replaced with "decide how many data points you need to collect." The instructions would also prompt students to then reflect on their results and think how they might improve them, with collecting additional data as one option. Each of the activities are described in more detail in Table II, along with additional detail about the lab activities used in the study.

The researcher observed one of the intervention condition lab sections each week and met with the instructor to debrief briefly about the activities. Several modifications were made to the lab materials on the fly. All analysis was carried out on the final set of materials implemented.

Three of the lab sessions from each term were not included in the analysis because they differed substantially from the rest of the labs. One of the excluded lab sessions, which was always held around the time of the midterm

\begin{tabular}{|c|c|c|c|c|c|c|}
\hline Control & $\begin{array}{c}\text { Lab A } \\
\text { (Uncertainty) }\end{array}$ & $\begin{array}{c}\text { Lab B } \\
\text { (Acceleration) }\end{array}$ & $\begin{array}{c}\text { Lab C } \\
\text { (Atwoods) }\end{array}$ & $\begin{array}{c}\text { Lab D } \\
\text { (Drag) }\end{array}$ & $\begin{array}{l}\text { Lab E } \\
\text { (Energy) }\end{array}$ & $\begin{array}{c}\text { Lab F } \\
\text { (Pendulum) }\end{array}$ \\
\hline & Week 1 & Week 2 & Week 3 & Week 4 & Week 6 & Week 7 \\
\hline Intervention & $\begin{array}{c}\text { Lab A } \\
\text { (Uncertainty) }\end{array}$ & $\begin{array}{c}\text { Lab F } \\
\text { (Pendulum) }\end{array}$ & $\begin{array}{l}\text { Lab C } \\
\text { (Atwoods) }\end{array}$ & $\begin{array}{c}\text { Lab D } \\
\text { (Drag) }\end{array}$ & $\begin{array}{c}\text { Lab B } \\
\text { (Acceleration) }\end{array}$ & $\begin{array}{l}\text { Lab E } \\
\text { (Energy) }\end{array}$ \\
\hline
\end{tabular}

$=$ Verification $\square=$ Evaluation

FIG. 2. Summary of the timing and types of labs throughout the courses. In verification labs, student investigations aimed to verify (demonstrate) a particular phenomenon or obtain a particular result (such as an estimate for acceleration due to gravity), implying low available epistemic agency. In evaluation labs, student investigations did not have any intended outcomes and students often had to collect data to evaluate multiple plausible models, implying high available epistemic agency. 
TABLE II. Lab activities performed by the students in both the control and intervention conditions, with differences in the lab week, type, and goal highlighted.

\begin{tabular}{|c|c|c|c|c|}
\hline Lab activity & Condition & Lab week & Lab type & Lab goal \\
\hline \multirow[t]{2}{*}{$\begin{array}{l}\text { A: Introduction to } \\
\text { uncertainty }\end{array}$} & Intervention & 1 & Evaluation & $\begin{array}{l}\text { Evaluated if the period of a pendulum differed with initial } \\
\text { angles of } 10 \text { degrees versus } 20 \text { degrees. }\end{array}$ \\
\hline & Control & 1 & Verification & $\begin{array}{l}\text { Measured pi by measuring the diameter and circumference of } \\
\text { circular objects and graphing the relationship. Practiced } \\
\text { using error propagation calculations. }\end{array}$ \\
\hline \multirow[t]{2}{*}{$\begin{array}{l}\text { B: The period of a } \\
\text { pendulum }\end{array}$} & Intervention & 2 & Evaluation & $\begin{array}{l}\text { Extension of Lab A, focusing on improving prior } \\
\text { investigations and designing experiments to evaluate the } \\
\text { nature of the difference. }\end{array}$ \\
\hline & Control & 7 & Verification & $\begin{array}{l}\text { Measured acceleration due to gravity by timing a pendulum's } \\
\text { period, after evaluating the effect of mass, length, and } \\
\text { angle on the period. }\end{array}$ \\
\hline \multirow{2}{*}{$\begin{array}{l}\text { C: Acceleration of } \\
\text { gravity using an } \\
\text { Atwood's machine }\end{array}$} & Intervention & 3 & Verification & $\begin{array}{l}\text { Measured acceleration due to gravity using an Atwood's } \\
\text { machine. }\end{array}$ \\
\hline & Control & 3 & Verification & $\begin{array}{l}\text { Verified a derived equation for the time it takes a mass to fall } \\
\text { a fixed distance. }\end{array}$ \\
\hline \multirow{2}{*}{$\begin{array}{l}\text { D: Air drag on coffee } \\
\text { filters }\end{array}$} & Intervention & 4 & Evaluation & \multirow{2}{*}{$\begin{array}{l}\text { Evaluated whether the drag force on coffee filters was } \\
\text { linearly or quadratically proportional to their terminal } \\
\text { velocity. }\end{array}$} \\
\hline & Control & 4 & Evaluation & \\
\hline \multirow{2}{*}{$\begin{array}{l}\text { E: Acceleration of } \\
\text { gravity using a } \\
\text { bouncing ball }\end{array}$} & Intervention & 6 & Verification & \multirow{2}{*}{$\begin{array}{l}\text { Estimated the acceleration due to gravity using a motion } \\
\text { sensor and a bouncing ball. }\end{array}$} \\
\hline & Control & 2 & Verification & \\
\hline \multirow{2}{*}{$\begin{array}{l}\text { F: Energy loss of a } \\
\text { bouncing ball }\end{array}$} & Intervention & 7 & Evaluation & \multirow{2}{*}{$\begin{array}{l}\text { Evaluated whether a bouncing ball loses energy primarily } \\
\text { through its collision with the table or through air resistance } \\
\text { as it travels. }\end{array}$} \\
\hline & Control & 6 & Evaluation & \\
\hline
\end{tabular}

exam, asked students to take measurements of a ballistic pendulum apparatus and predict where a projectile launched from the apparatus would land. The activity was framed as a competition between groups to identify who could more precisely and accurately predict the landing position. The other two excluded lab sessions were excel-based numerical analysis labs that did not involve any hands-on data collection or experimental design. These two labs took place at the end of the academic term in both conditions.

\section{Data sources and analysis}

All data came from the lab instructions provided to students and the written lab narratives students produced during the lab period. We analyzed the students' lab narratives for evidence of students' decision making through a coding scheme that is detailed below. We also analyzed the lab instructions for whether the associated decisions were made for students, cued for students to make, or not mentioned. To answer the first research question, we compared the structure between conditions and then compared the number of codes in students' lab narratives between conditions. To answer the second research question, we compared the number of codes in students' lab narratives with the type of investigation within conditions (either verification or evaluation activities). To answer the third research question, the narratives for two evaluation labs were also analyzed for the quality of students' decisions, in terms of coordination between theory and evidence and appropriate follow-up decisions. We then compared the quality of students' decisions on these two labs between the two conditions.

\section{Identifying agentic decision making}

We first identified the types of decisions recorded by students in their lab narratives. The codes were identified inductively as emergent patterns in the data [50]. Codes were developed that could be applied to all lab narratives and that described as many of the scientifically relevant decisions evidenced by the narratives as possible. The codes were then mapped onto three phases of agency: planning, executing, and reflecting. We do not expect that introductory students would have carried out all possible decisions needed for doing a science experiment [4]. The ones that they documented tell us where students had agency.

Much of the content in the students' narratives was not coded. For example, all groups described their methods 
TABLE III. Emergent codes indicating students' decisions and practices.

\begin{tabular}{|c|c|c|}
\hline & Code & Description \\
\hline Planning & $\begin{array}{l}\text { Assumptions } \\
\text { Expectations } \\
\text { Justifications } \\
\text { Piloting }\end{array}$ & $\begin{array}{l}\text { Students explicitly state assumptions about the physical or measurement systems. } \\
\text { Students explicitly list their expectations or predictions for the experimental result. } \\
\text { Students justify their experimental methods. } \\
\text { Students conduct a pilot investigation to evaluate the experimental setup. }\end{array}$ \\
\hline Executing & $\begin{array}{l}\text { Method changes } \\
\text { Data analysis changes } \\
\text { Data cleaning }\end{array}$ & $\begin{array}{l}\text { Students make modifications to the experimental method while collecting data. } \\
\text { Students modify analysis methods on the fly. } \\
\text { Students refine their collected data (mostly removing erroneous measurements). }\end{array}$ \\
\hline Reflecting & $\begin{array}{l}\text { Design improved precision } \\
\text { Design extensions } \\
\text { Propose testing equipment } \\
\text { Iteration } \\
\text { Going beyond }\end{array}$ & $\begin{array}{l}\text { Students describe ways to reduce their uncertainty. } \\
\text { Students describe new variables or measurements to explore. } \\
\text { Students describe possible tests of the equipment. } \\
\text { Students describe carrying out an improvement such as those above. } \\
\text { Students extend the investigation beyond the provided goal. }\end{array}$ \\
\hline
\end{tabular}

and the degree of agency in those descriptions was unclear. However, justifying the methods was a code that emerged as reflecting evidence of thoughtful decision making. We also did not evaluate the quality of these decisions in this round of coding.

We identified 12 separate decision making codes that fell into the three agency phases and represented the relevant decisions that students recorded (Table III). One rater coded all lab narratives and a second rater coded a randomly selected $10 \%$ portion of the data for comparison. Codes where the two raters could not come to agreement were removed. The final interrater reliability between coders was 0.90 (Cohen's kappa; [51,52]).

Related to planning, we identified four separate decisions in students' lab narratives. First was listing assumptions about the physical model, such as stating that the "mass of the string is negligible," "air density is constant," or "the shape of the filter remains the same throughout the fall." Second was listing expectations about the outcomes of the experiment, such as stating that "objects with greater mass will have greater terminal velocity" or sketching diagrams that represented expected graphs. Next were justifications to students' experimental designs, such as explaining that "The filters have to be dropped high enough to reach terminal velocity" or including sentences that started "we wanted to run three trials each because..." Finally, students also described pilot tests to understand or modify experimental set ups. For example, students described scrapping an initial plan to conduct multiple repeated trials because each measurement "takes a while, and terminal velocity won't vary by much within our experiment." Compared with simply describing the methods, these four types of decisions reflected students' agency in setting up the experiment [10].

Related to executing the experiment, we identified three types of decisions that followed from initial rounds of data collection. These decisions related to modifying methods (such as reducing movement in the system or timing a pendulum swing for ten periods instead of one), analysis (for example, creating a different graph, using a different equation), or data (such as removing outlying data points). These decisions represent taking personal control while conducting the experiment and responding to their setup and data [10].

Related to reflecting on the outcomes of the experiment, we identified five different behaviors that came after collecting data. These included suggestions for three kinds of subsequent investigations. First were suggestions to reduce uncertainty, such as "make the drop higher so that there is time for the filters to reach terminal velocity," or "have only one person take the times to reduce inconsistency." Next were suggestions to extend the investigation, such as proposing to test the impact a different surface has on the energy loss of a bouncing ball. Third was suggestions to test the equipment, such as proposing to test the motion sensor to understand the sensor range. The final two codes included evidence of students carrying out the previous suggestions (iteration) and other evidence that represented investigations going beyond the lab materials provided by the instructor. For example, one group built a drop chamber to consistently drop a ball, while another discussed the implications of the lab results to a novel situation. While we categorize this final category as reflection, it could be interpreted as a new form of intentionality and planning.

The grouping of the codes into the agency phases was based on the position of the action within the lab narrative. For example, if predictions for the experiment were listed at the start of the lab narrative before recording any collected data, it was coded as an expectation. Whereas, if students wrote that their results matched their expectations after the data and results were recorded in the lab narrative, without having those expectations stated earlier, the behavior was not coded as an expectation.

To further distinguish students' engagement in decision making with taking up available agency, we examined the 
tone of students' methods sections of the lab narratives. Writing their descriptions using first-person pronouns (through descriptions of either what they did or will do) demonstrates personal agency in that they have placed themselves into the narrative, indicating personal responsibility for the decisions and future planning [10,53-55]. While this may be idiosyncratic amongst individual students, any measurable, systematic differences between conditions can be attributed to the interventions. Students' methods were coded as either first person (descriptions of what they will do or descriptions of what they did), third person (instructions to someone else), or none provided. The combination of these pieces of evidence (tone and decision making), rather than either on their own, speak to students opting to take up the available agency.

\section{Identifying structure to support agency}

Students' decision codes may or may not have been cued in the instructions. Therefore, the lab instructions were separately coded using the same coding scheme after the 12 decision making codes were identified from the lab narratives. For each code, the instructions were analyzed as to whether they made the decision for the students, cued the students to make the decision, or provided no reference to the decision. For example, the instructions may have told students that the given model assumed that friction was negligible (decision given), may have cued students to identify the assumptions of the model (decision cued), or may have made no mention of the assumptions of the model. More structure (less agency) took precedence over less structure (more agency). That is, if instructions first cued a decision (for example, asked students to consider the assumptions of the model), and then gave them the decision (for example, later said that the model assumes friction was negligible), the instructions would be coded as "given."

\section{Identifying decision making quality}

To evaluate the quality of students' decisions (and answer the third research question), we examined how students coordinated theory and evidence when making two key decisions: (i) how they interpreted and acted on initial results from the experiment, and (ii) whether their conclusions were supported by their data. This was done for labs D and E, which were classified as evaluation labs for both conditions and involved the same nontrivial comparison between data and possible models (Table II). In lab D, students were asked to explore the relationship between the terminal velocity of falling coffee filters and the mass, and were presented with two plausible relationships (linear or quadratic). In lab E, students were asked to investigate if the energy loss of a bouncing ball was due to the collision of the ball with the ground or air resistance while moving. Lab E, including the fruitful learning opportunities therein, was recently described in Ref. [56]. We used the two common evaluation labs to evaluate the quality of students' decision making because we expected that the coordination of theory and evidence in verification labs would be impeded by potential confirmation biases or orientations [57-59]. Lab D may be classified as better affording epistemic agency than lab $\mathrm{E}$, because there is an intuitive expectation for the result in lab $\mathrm{E}$ (that the collision with the ground would result in more energy loss than drag).

We first categorized each group's observed results based on our visual analysis of the graphs they produced. In lab D, graphs were characterized as follows: (1) linear model fit the data better visually; (2) quadratic model fit the data better visually; (3) both models fit about the same; or (4) other. In lab E, students' graphs were characterized as follows: (1) a clear stepwise function (suggesting energy was lost in the collision); (2) a linear downward function (suggesting energy was constantly lost due to air resistance); (3) a rising step function (suggesting that energy was lost between bounces, but gained during air travel); or (4) other. In lab E, the different graphs typically resulted from different ways of converting position versus time data to velocity versus time (particularly, there was confusion about which time point corresponding to which velocity value).

Students' interpretations and conclusions were coded based on their narrative statements. In lab $\mathrm{D}$, the interpretation codes were as follows: (1) the terminal velocity and mass were related linearly; (2) the terminal velocity and mass were related quadratically, (3) the data were inconclusive; (4) other interpretation; or (5) no interpretation or conclusion was provided. In lab E, the interpretation codes were as follows: (1) the collision was the main source of energy loss; (2) air resistance was the main source; (3) collision and air resistance both contributed to the energy loss; or (4) no interpretation or conclusion was provided.

In both labs, we categorized any follow-up decisions students documented in their lab narratives as either (1) exploring or investigating their results or (2) doing nothing. Exploring results took on many different forms including taking additional data, conducting different experimental measurements, or carrying out a different analysis. A subset of narratives were coded by two independent raters and conflicts between raters were resolved through discussion. Initial interrater reliability was 0.81 for lab D and 0.85 for lab E using Cohen's kappa. One rater coded the remaining narratives.

Finally, we collapsed the codes into categories of (1) coordinating results and evidence with follow-up investigations and (2) coordinating results and evidence with conclusions. Coordinating results with follow-up investigations was collapsed into three categories: whether students explored expected results, explored ambiguous or conflicting results, or did not explore results. Coordinating results with conclusions was also collapsed into three categories: whether conclusions were supported by data, conclusions were unsupported by data, or no conclusion was provided. 


\section{Statistical analyses}

All statistical analyses were performed in $R$ [60]. We performed a linear regression to compare the number of coded decisions for each group across condition, lab week, and lab type (evaluation or verification). The number of coded decisions was identified as the number of unique codes present within each lab narrative. Repeat instances of a code were not counted more than once. The model that included interactions between both (a) condition and lab type and (b) condition and time were found to be the best model based on the explained variance $\left(R^{2}\right)$ and the Akaike information criterion (AIC). Rather than performing analyses separately for the two research questions, we included all variables in a single analysis to limit the number of comparisons and to obtain a more complete picture of the impacts on student decision making. To check the statistical effect of the variables overall, we also conducted an ANOVA with the same final regression function.

We performed an ordinal logistic regression to compare the tone of students' methods across condition and lab week. The tone was coded according to increasing evidence of agency: no method provided; instructions to someone else; descriptions of what they did in the past, and; descriptions of what they will do in the future. The ordinal logistic regression was performed in $R$ using the ordered logistic or probit regression function in the MASS package [61]. Condition and lab week were used as variables (both coded as factors) and models with and without the interaction were evaluated. The model without the interaction was found to be a better model based on the AIC, and the interaction was nonsignificant. ANOVA tables for the regression were found using the Anova function in the car package [62].

Finally, we performed chi-squared tests of independence to compare conditions on the quality of student decisions across the three categories for each comparison (coordinating results with follow-up decisions, and coordinating results with conclusions).

\section{RESULTS}

We present the results according to our three research questions: quantity of decision making versus decision making structure, quantity of decision making versus epistemic agency, and quality of decision making between conditions.

\section{A. Quantity of decision making versus structure}

Our first research question probed the relationship between the quantity of students' decision making and the amount and type of structure provided to them (either through decisions made for them, decision making cued or prompted, or decisions left open). We evaluated the quantity of students' decision making in terms of the number of decision-making codes (Table III) students recorded in their lab narratives (decision-making agency taken up). We contrasted the students' decision making with the structure in the instructions in terms of which decision-making codes were made for the students, cued to students, or left open (decision making agency available). We related this decision making to taking up agency by also evaluating the tone of students' methods.

\section{Decision-making agency afforded by the lab instructions}

As shown in Fig. 3, the instructions in the intervention condition cued students to make more decisions than in the control condition. For the intervention condition, only one decision in one lab was given to students (Planning in Week 6) -all other decisions were either cued or left open. In the control condition, students were given most of the decisions for planning (darker bars in the top panel of Fig. 3), with very little structure for executing and reflecting. The intervention condition similarly had little structure for executing, but many cues for reflecting. Overall, there was more structure in the intervention condition when summing the total number of decisions cued or given, and this structure was faded over time.

\section{Decisions made by students}

Figure 4 shows the average number of coded decisions per group between labs and conditions (where number of coded decisions refers to the unique codes present in each lab narrative). Students in the control condition recorded significantly fewer decision codes than students in the intervention condition: $F(1,275)=483.85, p \ll 0.001$, with a moderate effect size: $\eta_{\text {partial }}^{2}=0.64$. On average, students in the intervention condition made 2.5 decisions per lab, while students in the control condition averaged 0.25 decisions per lab; lower by a factor of ten. There were also statistically significant differences across lab weeks: $F(5,275)=12.28, p \ll 0.001$; but the trend over time was varied by condition: $F(3,275)=20.20, p \ll 0.001$, with small effect sizes: $\eta_{\text {partial }}^{2}=0.18$ in both cases. Details are provided in Table $\mathrm{V}$ and Table VI.

Importantly, the number of coded decisions per group did not increase monotonically over time. Nor did any condition reach anywhere near the total number of decision codes (12). We can also compare the number of student decisions coded to the total decisions available for them to make (i.e., the number either cued or not mentioned, rather than given). The control condition, on average, documented $4 \%$ of the available decisions in a given week (2\%-6\% depending on the week). The intervention condition documented $22 \%$ of the available decisions, in a given week on average (13\%-31\% depending on the week). We also can compare the number of coded student decisions to the number of decisions cued in the instructions. The control condition made 0.35 times as many decisions as were cued in the instructions (0.25-0.50 depending on the week) 


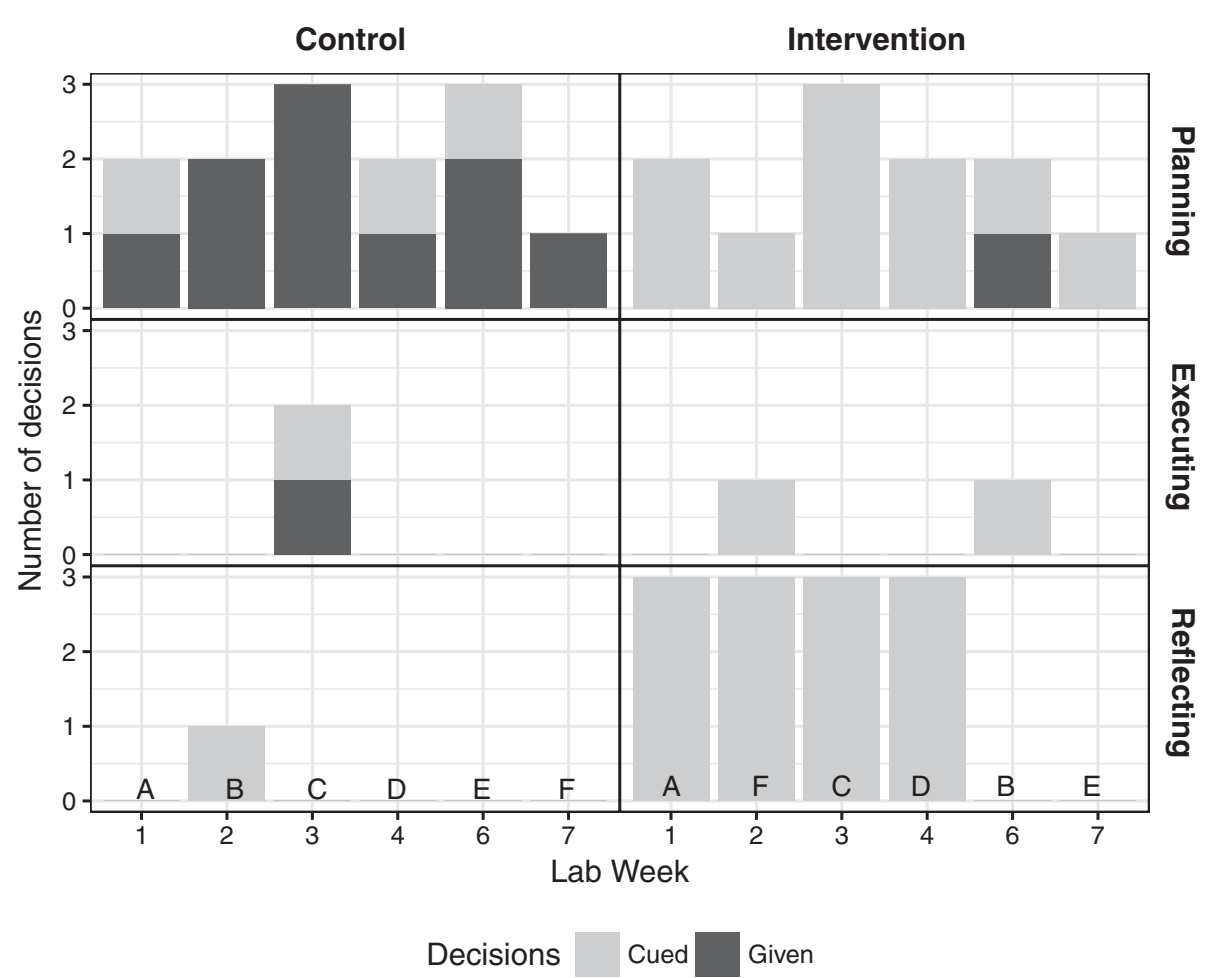

FIG. 3. The number of agency-based decisions provided in the instructions across labs and conditions. The instructions either made decisions for the students (given) or cued students to make decisions (cued). The instructions in the control condition made many planning decisions for the students, but provided little structure for executing and reflecting. The instructions in the intervention condition had more structure overall, but this structure was almost exclusively in the form of cues and the structure was faded over time.

while the intervention condition made 0.96 times as many decisions as were cued. Consistent with the previous analysis, the ratio for the intervention condition was lowest in the first lab (1.5 student decisions coded to 5 decisions cued) and highest in the final lab (2.75 student decisions coded to 1 decision cued).

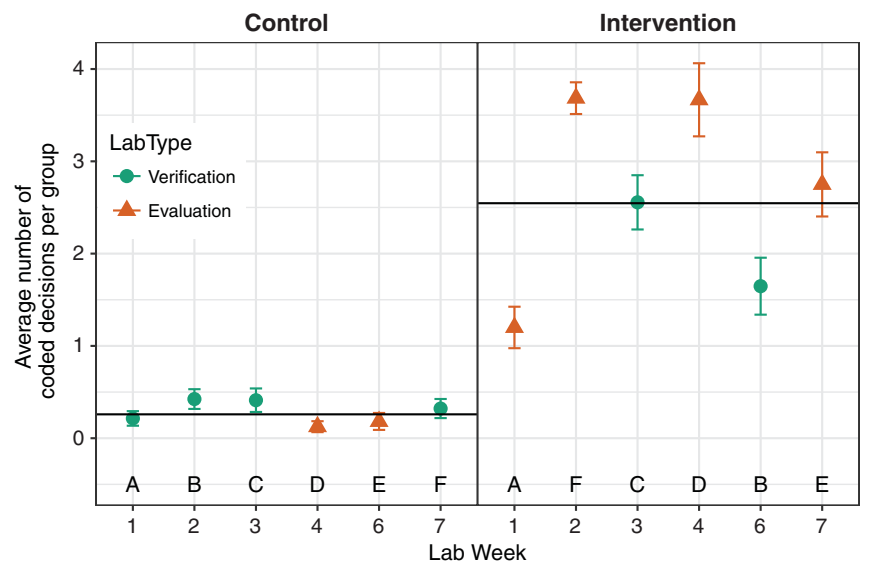

FIG. 4. Average number of coded decisions per group across labs, conditions, and lab types. The error bars represent the standard errors of the means. The horizontal lines indicate the condition average across labs. The lab activity labels associated with each lab week are indicated along the $x$ axis.

\section{Agency through students' tone}

As shown in Fig. 5, another manifestation of greater agency in the intervention group was in students' description of their methods. Students in the intervention condition were much more likely to use the first person to describe what they had done and what they will do than students in the control condition, but this did not vary over time (Table VII). This result was confirmed in an ANOVA analysis, which found a significant effect for lab condition: $\chi^{2}(1)=13.97, p \ll 0.001$; but a nonsignificant effect for lab week: $\chi^{2}(5)=2.22, p \ll 0.819$. These results suggest that students in the intervention condition were personally engaged in the agentic decision making, rather than simply following instructions, supporting the previous analysis.

\section{B. Quantity of decision making versus available epistemic agency}

Our second research question focused on the impact of affording epistemic agency (labs that aimed to evaluate rather than verify phenomena) on the quantity of students' decision making. Figure 4 shows that groups in the intervention condition recorded fewer decisions in the verification labs than in the evaluation labs, with the exception of the first lab. A more detailed discussion of this exception can be found in Sec. IV. The statistical analyses support this interpretation (Table V and Table V). 


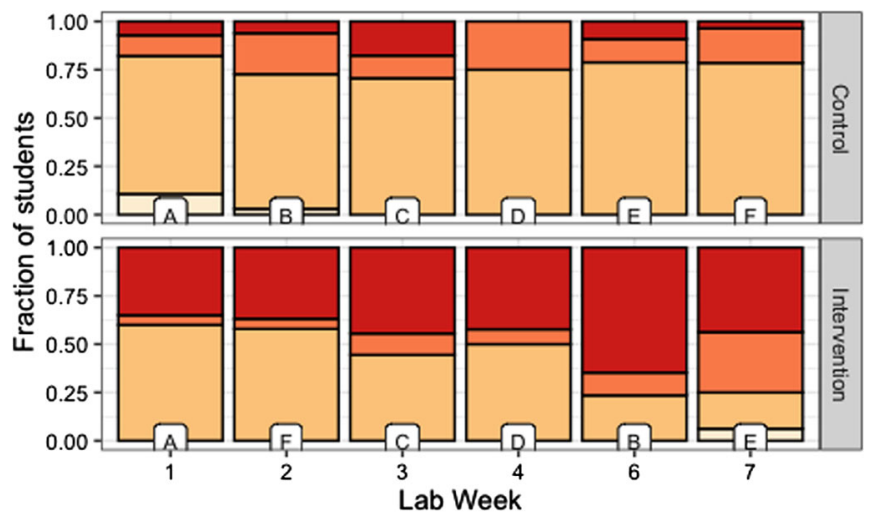

Tone

Descriptions of what they will do

Instructions to someone else

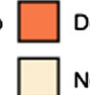

Descriptions of what they did None provided

FIG. 5. The fraction of students who wrote their lab methods in various tones (either third-person narratives as instructions to someone else or first-person narratives as descriptions of what they did in the past or of what they will do in the future) across labs and conditions. By weeks six and seven, the fraction of students describing what they will do differs by a factor of 10 between conditions, suggesting personal agency in the intervention condition.

\section{Impact of agency on decision-making quality}

Our third research question probed the impacts on the quality of students' decision making. We focused on decisions related to responding to initial results and formulating conclusions, with quality indicated through coordination with evidence. From Table IV, we see that students in the intervention condition were more likely to explore their initial results regardless of the outcome and were more likely to draw conclusions supported by their data than students in the control condition. The differences by condition were statistically significant for whether and how they explored their results: $\chi^{2}(2)=41.92, p \ll 0.001$; and the alignment between data and conclusions: $\chi^{2}(2)=7.10, p=0.029$. The fraction of students in the intervention condition exploring expected results is particularly surprising.

TABLE IV. Percent of student groups engaging in various scientific (and nonscientific) practices across labs D and E. Differences between conditions were statistically significant.

\begin{tabular}{lcc}
\hline \hline Exploration & Control & Intervention \\
\hline Exploring ambiguous & $5 \%$ & $42 \%$ \\
$\quad$ or conflicting results & & \\
Exploring expected results & $0 \%$ & $21 \%$ \\
Not exploring results & $95 \%$ & $36 \%$ \\
Conclusions & Control & Intervention \\
Conclusions supported by data & $45 \%$ & $70 \%$ \\
Conclusions contradict data & $52 \%$ & $24 \%$ \\
No conclusion provided & $3 \%$ & $6 \%$ \\
\hline \hline
\end{tabular}

In lab D, no students in the control condition explored their initial results, even when their data were inconclusive or ambiguous. Several groups concluded that the linear model was the better fit when the quadratic was visually more appropriate. Control students were also more likely to draw conclusions from ambiguous results, most often claiming that the quadratic model was a better fit when the two models were indistinguishable.

In lab E, students in both conditions obtained initial results that fell within all four categories. Despite this variability, nearly all students in the control condition came to the expected conclusion that energy was lost in the collision, despite only half the groups having data to clearly support the conclusion. Only three groups in the control condition explored their results. Students in the intervention condition again were more likely to explore their results, regardless of the initial outcomes. This exploration resulted in students collecting new data or revising their analysis to produce data that supported their conclusion. Only two groups in the control out of 11 addressed the conflict between their prior knowledge (namely, that the collision with the floor would result in most energy loss) and their results (namely, that air resistance is the primary source of energy loss). By contrast, all four groups who reached this result in the intervention condition explored their results and ultimately found the effect of the collision.

\section{DISCUSSION}

In this paper, we evaluated two instructional lab formats with similar lab activities, but with very different levels of structure and available decision making agency. Both formats included a combination of labs that aimed to verify known results (low epistemic agency) and labs where there was no apparent right answer (high epistemic agency). Both formats aimed to develop students' measurement, uncertainty, and data analysis skills and used the same six lab setups, but differed in the associated instructions. The instructions in the intervention condition provided more but different structure than in the control condition. Instructions in the control condition more often made decisions for students, primarily associated with the planning and set up of the investigations, while instructions in the intervention condition cued which decisions should be made. The intervention condition also included structure for reflecting on the investigation.

We found that students in the intervention condition engaged in much more substantial decision making than students in the control condition. Students in the intervention condition were found to record decisions and justifications about their experimental plan, reflect on and respond to their experiment while executing their plan, and reflect on their results to propose and carry-out improvements at a rate ten times larger than the control condition. Students in the intervention condition even recorded more decisions in weeks six and seven when structure was reduced. 
This suggests that students learned to make such decisions with limited prompting, possibly adopting them as scientific practice. The low number of decisions made in the first week suggests that students took time to take up the available agency. The number of decisions, however, did not increase steadily over time. Future work should evaluate the process and time evolution of how students' expectations and behaviors shift in these new types of labs.

Students in the control condition recorded very few decisions, indicating very little agency. The few coded decisions for students in the control condition were predominantly suggestions for improving the experiment. These were mostly vague statements (such as "take more data") or impractical suggestions (such as using unavailable equipment), and students did not act on them. In contrast, students in the intervention condition made specific suggestions for improvement and then acted upon them.

The association between students' decision making and agency was also evident through differences in the tone of students' descriptions of their methods in their lab narratives. Students in the control condition almost exclusively wrote their methods as instructions to someone else, while students in the intervention condition were more likely to write descriptions of what they did in the past or what they would do in the future, suggesting personal agency [53,54]. Combined with the increased number of coded decisions, these results suggest that students in the intervention condition took up decision making agency overwhelmingly more than the control group, beyond any individual variability in students' individual writing styles.

The results in this study provide more evidence for the mechanisms by which to engage students in scientific practice in instructional labs. Contributing to prior work, this study more critically evaluated the relationship between the structure of labs and students' resulting behaviors. The contrast between the two conditions is not a comparison of structure versus agency as two dichotomous variables. The balance of structure and agency available to students varied between conditions, across labs, and between elements of the experimentation process. The key distinction was not in the amount of structure, but rather the type: how this structure was provided. The instructions in the intervention condition actually provided more structure than the control condition in terms of how many decisions they explicitly mentioned, but the decisions were cued for students to make. This afforded agency to the students while supporting them in navigating the vast array of possible decisions involved in experimentation. For the control condition, decisions were mostly made for the students or not mentioned at all. While previous studies attempted to provide opportunities for student agency by removing structure [63-65], our results suggest that learning the decision making associated with scientific practice requires some imposed structure.

Nor are the results a demonstration that students simply followed instructions. For example, while six different decisions were cued in the third lab in the intervention condition, students, on average, only recorded 2.5 decisions. On the other hand, we saw that when the cueing was reduced in the intervention condition in the final two weeks (labs B and E), students continued to make decisions at a rate similar to before. This result suggests that the structure in prior labs developed students' habits of mind and expectations of behaviors that continued into subsequent labs, implying the learning (or adoption) of scientific practice. Combined, these results support the claim that students engaged in agentic decision making, rather than simply following instructions.

The greater adoption of scientific practices by the intervention group was also reflected through the quality of their decisions. Students in the intervention condition were more critical in investigating and exploring initial results before drawing conclusions, evaluating and resolving ambiguous or surprising results, and presenting conclusions that were supported by their data. This result supports our premise that providing opportunities for students to take up agency in conducting their experiments, with sufficient support, develops their scientific practices. These results also indicate students' improved critical thinking generally, which has been found in these types of labs previously [6].

The study also found that the number of recorded decisions by the intervention group varied over time, with a stark increase after the first week. This result further motivates that the structure alone is insufficient to produce the observed behaviors. The few coded decisions during the first suggests that students took time to orient to the available agency and instructional format in the labs. This orientation may have been in response to the feedback from the instructor, a feature of the first lab, or simply a demonstration that students were learning the associated decision making skills, in line with literature arguing that students can take several weeks to develop various scientific practices [7]. Future work should further evaluate this development and how students transition into these labs, which likely afford more agency than their prior lab experiences.

Student decision making was also strongly influenced by the epistemic agency available through the type of lab activity being conducted. In verification labs, where the goal was to obtain an outcome to verify a particular result, students in the intervention condition recorded fewer agency-based decisions than in evaluation labs, where the goal was to evaluate a model or compare multiple possible models. Previous research has suggested that when students know the intended result of the experiment, they may feel encouraged to "massage their data" [23] or engage in questionable research practices to get the expected outcome [57-59]. Evaluation labs (at least for the intervention condition) encouraged revision and exploration, likely because there was no clear end point to pursue [66]. 
This is particularly evident given that nearly a quarter of students in the intervention condition explored expected results. Notably, benefits from supporting epistemic agency were observed even though the investigation goal was provided to students. In the same way that supporting decision making agency involved providing extensive structure, epistemic agency was also supported in a structured form. This is in stark contrast to more openended or inquiry learning environments, where students choose their own research questions to pursue. Furthermore, the topics of these activities were not pursuing questions whose answers are unknown to scientists, as in CUREs [45]. While the answers were unknown to the students, they had previously been investigated, and the likely answers were known to the instructor. From this work, it is unclear whether more epistemic agency as in these two contrasting forms (defining your own question or pursuing authentic questions) would improve student decision making. Recent work has proposed that the pursuit of an authentic research question is not necessary for the learning benefits from CUREs [46,47]. Future research should probe the benefits of supporting agency (both epistemic and decision making) across the spectrum of possibilities, and how varied levels of agency and structure may impact different students or instructional situations. Given the results when more decision making agency was available over time, it is likely that available epistemic agency could also be increased over time, such that a course builds towards students designing their own research questions.

Finally, the results also indicate that prior work with these types of labs are generalizable to two-year, community college populations, contributing to the dearth of evidence on community college instruction [24,67]. It is clear that these students took up the available agency and engaged in high-quality scientific decision making. In these results, however, all decision making was a product of the group, rather than the individual. Future work should further evaluate the contributions of individual students and the engagement of subpopulations of students in the decision-making processes, as research suggests that different students will likely interact with the levels of available agency and structure differently [68].

\section{A. Limitations and future work}

Our data and results are limited in several ways. First, we note that the coded decisions are not independent of one another. When a group decided to collect more data, for example, it was very common that they would also modify their data-gathering approach in some way. Therefore, one decision often ended up fulfilling more than one coding category, leading to further decisions. This, however, demonstrates the power of the intervention: by cueing a specific decision, a cascade of related decisions and experimental behaviors are triggered.
Second, while students in both conditions were encouraged to $\log$ all of their decisions, results, and activities throughout the labs, there were likely many discussions and decisions made between students that were not recorded. We also do not have record of the role of the instructor in the different labs. From previous work, we know there is a danger of instructors providing verbal instructions that entirely eliminate agency. From observations of the intervention lab, however, it was clear that the instructor fruitfully supported and encouraged student agency. We also did not have access to the feedback the instructors provided to the students on their lab narratives, which likely contributed messaging about the decision making expectations. Future work should use video or in-class observations to characterize, in more depth, the ways in which students take up agency in the lab and interact with various levels of structure and feedback in the classroom, from both the instructor and their peers.

Third, our results suggested ways that students' decision making evolved over time, but could not isolate the effect of time, structure, epistemic agency, or even relevant physics content. In particular, studies should aim to replicate and understand the low number of decisions made in the first lab session.

While we have demonstrated improvements in students' scientific practices as a result of supporting student agency, we did not explore the impact on students' attitudes, motivation, or self-efficacy, which has been associated with agency previously $[10,16,53,69-71]$. This remains an interesting area for future work. Finally, introductory college students tend to believe that experimentation is meant to verify theory $[44,72]$. Supporting epistemic agency in the labs will likely improve this perspective of the nature of experimental science more broadly and should be studied.

We also did not probe the interactions between different levels of epistemic agency and decision-making agency. For example, in a confirmatory investigation, students may have limited epistemic agency as they are expected to confirm or verify an idea from class, but extensive decision making agency to decide how to find the desired result [73]. Similarly, students may have limited decision-making agency in an authentic research experience where a mentor has provided step-by-step instructions to follow, but have high epistemic agency as the activities are in pursuit of cutting edge knowledge [23]. These relationships should be explored in future work.

\section{ACKNOWLEDGMENTS}

We would like to thank the lab instructors, particularly David Marasco, for their support and bravery to learn with us. We also thank the Wieman group and the Cornell Physics Education Research Lab for useful feedback on this manuscript. 


\section{APPENDIX: REGRESSION AND ANALYSIS TABLES}

Here we provide analysis tables for the statistical tests described in the main text. Table $\mathrm{V}$ presents the linear regression analysis for the total number of coded behaviors across conditions, time, and lab type. Table VI presents the ANOVA for the regression analysis for Model 2 in Table V. The ANOVA indicates the overall importance of each of the variables in the model, while the regression table provides the effect sizes for each level of each variable. Table VII presents the ordinal logistic regression analysis for the tone of students' descriptions of their methods between conditions and over time.

TABLE V. Linear regression analysis for the total number of coded behaviors across conditions, lab weeks, and lab types (evaluation or verification). The variable estimate is listed with its standard error for models with and without interaction terms. The base is a student in the control condition, in an evaluation lab, in week 1 . Note that the interaction terms between condition and time for weeks 4 and 6 are exactly redundant with interactions with condition and lab type, and so are omitted from the regression.

\begin{tabular}{lcc}
\hline \hline Predictor & Model 1 & Model 2 \\
\hline Intercept & $-0.22(0.18)$ & $-2.34(0.31)^{* * *}$ \\
Condition (Intervention) & $2.26(0.13)^{* * *}$ & $3.54(0.25)^{* * *}$ \\
Lab week (2) & $1.12(0.19)^{* * *}$ & $0.21(0.22)$ \\
Lab week (3) & $0.78(0.21)^{* * *}$ & $0.20(0.21)$ \\
Lab week (4) & $0.80(0.21)^{* * *}$ & $0.21(0.02)^{* * *}$ \\
Lab week (6) & $0.19(0.20)$ & $2.47(0.27)^{* * *}$ \\
Lab week (7) & $0.71(0.20)^{* * *}$ & $0.11(0.22)$ \\
Condition (intervention): Lab week (2) & $\ldots$ & $2.27(0.34)^{* * *}$ \\
Condition (intervention): Lab week (3) & $\ldots$ & $3.23(0.53)^{* * *}$ \\
Condition (intervention): Lab week (7) & $\ldots$ & $1.44(0.36)^{* * *}$ \\
Lab type (verification) & $-0.17(0.16)$ & $2.56(0.35)^{* * *}$ \\
Condition (intervention): Lab type (verification) & $\ldots$ & $-4.63(0.61)^{* * *}$ \\
AIC & 792.83 & 727.98 \\
BIC & 825.77 & 775.55 \\
$R_{\text {adj }}^{2}$ & 0.60 & 0.68 \\
\hline$* p<0.05, * * p<0.01, * * * p<0.001$. & &
\end{tabular}

TABLE VI. Type-1 ANOVA for the total number of coded behaviors across conditions, lab weeks, and lab types (evaluation or verification).

\begin{tabular}{lcccc}
\hline \hline Independent variable & $d f$ & $F$ & $\eta_{\text {partial }}^{2}$ & $p$ \\
\hline Condition & 1 & 483.85 & 0.64 & $\ll 0.001^{* * *}$ \\
Lab type & 1 & 1.34 & 0.004 & 0.247 \\
Lab week & 5 & 12.28 & 0.18 & $\ll 0.001^{* * *}$ \\
Condition*type & 1 & 18.87 & 0.06 & $\ll 0.001^{* * *}$ \\
Condition*time & 3 & 20.20 & 0.18 & $\ll 0.001^{* * *}$ \\
Residuals & 275 & & & \\
\hline
\end{tabular}

TABLE VII. Ordinal logistic regression analysis for the tone of students' descriptions of their methods between conditions and over time. The variable estimate is listed with its standard error for models with and without interaction terms. The base is a student in the control condition in week 1.

\begin{tabular}{lc}
\hline \hline Predictor & Estimate \\
\hline Condition & $0.91(0.24)$ \\
$\quad$ (intervention) & \\
Lab week (2) & $0.15(0.42)$ \\
Lab week (3) & $0.27(0.44)$ \\
Lab week (4) & $0.13(0.41)$ \\
Lab week (6) & $0.28(0.41)$ \\
Lab week (7) & $0.58(0.43)$ \\
AIC & 572.3 \\
Residual deviance & 554.3 \\
\hline \hline
\end{tabular}


[1] A Framework for K-12 Science Education: Practices, Crosscutting Concepts, and Core Ideas, edited by $\mathrm{H}$. Quinn, H. A. Schweingruber, and T. Keller (National Academies Press, Washington, DC, 2012), p. 400.

[2] President's Council of Advisors on Science and Technology, Engage to Excel: Producing one million additional college graduates with degrees in science, technology, engineering, and mathematics, Tech. Rep. (Executive Office of the President, Washington, DC, 2012).

[3] A. M. Phillips, J. Watkins, and D. Hammer, Beyond asking questions: Problematizing as a disciplinary activity, J. Res. Sci. Teach. 55, 982 (2018).

[4] C. Wieman, Comparative cognitive task analyses of experimental science and instructional laboratory courses, Phys. Teach. 53, 349 (2015).

[5] M. J. Ford, Educational implications of choosing "practice" to describe science in the Next Generation Science Standards, Sci. Educ. 99, 1041 (2015).

[6] N. G. Holmes, C. E. Wieman, and D. A. Bonn, Teaching critical thinking, Proc. Natl. Acad. Sci. U.S.A. 112, 11199 (2015).

[7] E. Etkina, A. Karelina, and M. Ruibal-Villasenor, How long does it take? A study of student acquisition of scientific abilities, Phys. Rev. ST Phys. Educ. Res. 4, 020108 (2008).

[8] J. Arnold and D. J. Clarke, What is 'Agency'? Perspectives in science education research, Int. J. Sci. Educ. 36, 735 (2014).

[9] M. Emirbayer and A. Mische, What is agency?, Am. J. Sociology 103, 962 (1998).

[10] A. Bandura, Human agency in social cognitive theory, Am. Psychol. 44, 1175 (1989).

[11] R. Paternoster and G. Pogarsky, Rational choice, agency and thoughtfully reflective decision making: The short and long-term consequences of making good choices, J. Quant. Criminol. 25, 103 (2009).

[12] M. Luck and M. D 'inverno, A formal framework for agency and autonomy, in First International Conference on Multiagent Systems, edited by L. Gasser and V. Lesser (American Association for Artificial Intelligence Press, San Francisco, CA, 1995), pp. 254-260.

[13] C. P. Niemiec and R. M. Ryan, Autonomy, competence, and relatedness in the classroom, School Field 7, 133 (2009).

[14] M. F. Crane, The differential impact of agency and pathway thinking on goal pursuit and university exam performance, Personality Indiv. Diff. 58, 20 (2013).

[15] J. Pym and R. Kapp, Harnessing agency: Towards a learning model for undergraduate students, Studies Higher Educ. 38, 272 (2013).

[16] A. Bandura and Albert, Self-efficacy mechanism in human agency, Am. Psychol. 37, 122 (1982).

[17] A. Bandura, Exercise of human agency through collective efficacy, Curr. Dir. Psychol. Sci. 9, 75 (2000).

[18] M. I. Mafra Goulart and W.-M. Roth, Engaging young children in collective curriculum design, Cultural Studies Sci. Educ. 5, 533 (2010).

[19] P. Renshaw, On the notion of worthwhile agency in reformist pedagogies, Learn. Culture Social Interact. 10, 60 (2016).
[20] A. Mäkitalo, On the notion of agency in studies of interaction and learning, Learn. Culture Social Interact. 10, 64 (2016).

[21] M. I. Mafra Goulart and W. Roth, Margin — centre: Toward a dialectic view of participation, J. Curric. Stud. 38, 679 (2006).

[22] B. A. Brown, Intellectual innovation or intellectual retrofitting: On agency, culture and access to science education, Cultural Studies Sci. Educ. 4, 379 (2009).

[23] N. G. Holmes and C. E. Wieman, Examining and contrasting the cognitive activities engaged in undergraduate research experiences and lab courses, Phys. Rev. Phys. Educ. Res. 12, 020103 (2016).

[24] S. R. Singer, N. R. Nielsen, and H. A. Schweingruber, Discipline-based education research: understanding and improving learning in undergraduate science and engineering, Tech. Rep. (Committee on the Status, Contributions, and Future Directions of Discipline-Based Education Research; Board on Science Education; Division of Behavioral and Social Sciences and Education; National Research Council, Washington, DC, 2012).

[25] S. R. Singer, M. L. Hilton, and H. A. Schweingruber, America's lab report: Investigations in high school science, Tech. Rep. (Committee on High School Science Laboratories: Role and Vision; National Research Council, Washington, DC, 2005).

[26] B. R. Wilcox and H. J. Lewandowski, Open-ended versus guided laboratory activities:Impact on students' beliefs about experimental physics, Phys. Rev. Phys. Educ. Res. 12, 020132 (2016).

[27] B. R. Wilcox and H. J. Lewandowski, Developing skills versus reinforcing concepts in physics labs: Insight from a survey of students' beliefs about experimental physics, Phys. Rev. Phys. Educ. Res. 13, 010108 (2017).

[28] N. G. Holmes, J. Olsen, J. L. Thomas, and C. E. Wieman, Value added or misattributed? A multi-institution study on the educational benefit of labs for reinforcing physics content, Phys. Rev. Phys. Educ. Res. 13, 010129 (2017).

[29] C. Wieman and N. G. Holmes, Measuring the impact of an instructional laboratory on the learning of introductory physics, Am. J. Phys. 83, 972 (2015).

[30] E. Etkina, A. Karelina, M. Ruibal-Villasenor, D. Rosengrant, R. Jordan, and C. E. Hmelo-Silver, Design and reflection help students develop scientific abilities: Learning in introductory physics laboratories, J. Learn. Sci. 19, 54 (2010).

[31] J. Osborne, Teaching scientific practices: Meeting the challenge of change, J. Sci. Teach. Educ. 25, 177 (2014).

[32] B. R. Belland, C. Kim, and M. J. Hannafin, A framework for designing scaffolds that improve motivation and cognition, Educ. Psychol. 48, 243 (2013).

[33] E. Etkina and A. Van Heuvelen, Investigative science learning environment-A science process approach to learning physics, in Reviews in PER Volume 1: Research-Based Reform of University Physics, edited by E. F. Redish and P. J. Cooney (American Association of Physics Teachers, College Park, MD, 2007), pp. 1-48.

[34] N. G. Holmes, J. Day, A. H. K. Park, D. A. Bonn, and I. Roll, Making the failure more productive: scaffolding the invention process to improve inquiry behaviors and outcomes in invention activities, Instr. Sci. 42, 523 (2014). 
[35] M. T. Chi, N. De Leeuw, M.-H. Chiu, and C. Lavancher, Eliciting self-explanations improves understanding, Cogn. Sci. 18, 439 (1994).

[36] I. Roll, N. Holmes, J. Day, and D. Bonn, Evaluating metacognitive scaffolding in guided invention activities, Instr. Sci. 40, 691 (2012).

[37] R.D. Pea, The social and technological dimensions of scaffolding and related theoretical concepts for learning, education, and human activity, J. Learn. Sci. 13, 423 (2004).

[38] A. Rajala, K. Kumpulainen, A. P. Rainio, J. Hilppö, and L. Lipponen, Dealing with the contradiction of agency and control during dialogic teaching, Learn. Culture Social Interact. 10, 17 (2016).

[39] W. H. Sewell, A theory of structure: Duality, agency, and transformation, Am. J. Sociology 98, 1 (1992).

[40] S. Barzilai and C. A. Chinn, On the goals of epistemic education: Promoting apt epistemic performance, J. Learn. Sci. 27, 353 (2018).

[41] M. Scardamalia and C. Bereiter, Knowledge building and knowledge creation: Theory, pedagogy, and technology, in The Cambridge Handbook of the Learning Sciences, edited by R. K. R. K. Sawyer and C. Bereiter (Cambridge University Press, New York, NY, 2014), pp. 397-417.

[42] D. Stroupe, Examining classroom science practice communities: How teachers and students negotiate epistemic agency and learn science-as-practice, Sci. Educ. 98, 487 (2014).

[43] L. Z. Jaber and D. Hammer, Engaging in science: A feeling for the discipline, J. Learn. Sci. 25, 156 (2016).

[44] D. Hu, B. M. Zwickl, B. R. Wilcox, and H. J. Lewandowski, Qualitative investigation of students' views about experimental physics, Phys. Rev. Phys. Educ. Res. 13, 020134 (2017).

[45] L. C. Auchincloss, S. L. Laursen, J. L. Branchaw, K. Eagan, M. Graham, D. I. Hanauer, G. Lawrie, C. M. McLinn, N. Pelaez, S. Rowland, M. Towns, N. M. Trautmann, P. VarmaNelson, T. J. Weston, and E. L. Dolan, Assessment of course-based undergraduate research experiences: a meeting report, CBE Life Sci. Educ. 13, 29 (2014).

[46] C. J. Ballen, S. K. Thompson, J. E. Blum, N. P. Newstrom, and S. Cotner, Discovery and broad relevance may be insignificant components of course-based undergraduate research experiences (CUREs) for non-biology majors, J. Microbiol. Biol. Educ. 19, 1515 (2018).

[47] S. Rowland, R. Pedwell, G. Lawrie, J. Lovie-Toon, and Y. Hung, Do we need to design course-based undergraduate research experiences for authenticity?, CBE Life Sci. Educ. 15, $\operatorname{ar} 79$ (2016).

[48] Foothill-De Anza Community College District, http:// research.fhda.edu/factbook/demographic-fact-sheets-fh .html (2017).

[49] Foothill-De Anza Community College District, http:// research.fhda.edu/factbook/foothill-demographic-trends .html (2017).

[50] A. Strauss and J. M. Corbin, Basics of Qualitative Research: Grounded Theory Procedures and Techniques (Sage Publications, Thousand Oaks, CA, 1998).

[51] J. Cohen, A coefficient of agreement for nominal scales, Educ. Psychol. Meas. 20, 37 (1960).
[52] K. A. Hallgren, Computing inter-rater reliability for observational data: An overview and tutorial, Tutor. Quant. Methods Psychol. 8, 23 (2012).

[53] A. C. Barton and E. Tan, We be burnin'! Agency, identity, and science learning, J. Learn. Sci. 19, 187 (2010).

[54] J. Martin, The grammar of agency: Studying possibilities for student agency in science classroom discourse, Learn. Culture Social Interact. 10, 40 (2016).

[55] S. Hitlin and G. H. Elder, Time, self, and the curiously abstract concept of agency, Soc. Theory 25, 170 (2007).

[56] D. Marasco, Teaching an old ball new tricks: Another look at energetics, motion detectors, and a bouncing rubber ball, Phys. Teacher 58, 62 (2020).

[57] M. M. Stein, E. M. Smith, and N. Holmes, Confirming what we know: Understanding questionable research practices in intro physics labs, in Proceedings of the 2018 Physics Education Research Conference, Washington, DC, edited by A. Traxler, Y. Cao, and S. Wolf (AIP, New York, 2018), https://doi.org/10.1119/perc.2018.pr.Stein.

[58] E. M. Smith, M. M. Stein, and N. G. Holmes, Surprise! Shifting students away from model-verifying frames in physics labs, in Proceedings of the 2018 Physics Education Research Conference Washington, DC, edited by A. Traxler, Y. Cao, and S. Wolf (AIP, New York, 2018), https://doi.org/10.1119/perc.2018.pr.Smith.

[59] E. M. Smith, M. Stein, and N. G. Holmes, How expectations of confirmation influence students' experimentation decisions in introductory labs, Phys. Rev. PER (to be published).

[60] R Core Team, R: A language and environment for statistical computing, Tech. Rep. (R Foundation for Statistical Computing, Vienna, Austria, 2016).

[61] W. N. Venables and B. D. Ripley, Modern Applied Statistics with $S$, 4th ed. (Springer, New York, 2002).

[62] J. Fox and S. Weisberg, An $\{R\}$ Companion to Applied Regression, 2nd ed. (Sage, Thousand Oaks, CA, 2011).

[63] E. Halstead, Effects of reducing scaffolding in an undergraduate electronics lab, Am. J. Phys. 84, 552 (2016).

[64] L. B. Buck, M. H. Towns, and S. L. Bretz, Research and teaching: Characterizing the Level of inquiry in the undergraduate laboratory, J. Coll. Sci. Teach. 38, 52 (2008).

[65] A. Morrison, From cookbooks to single sentences: The evolution of my labs, Phys. Teach. 52, 505 (2014).

[66] D. Katchevich, A. Hofstein, and R. Mamlok-Naaman, Argumentation in the chemistry laboratory: Inquiry and confirmatory experiments, Res. Sci. Educ. 43, 317 (2013).

[67] S. Kanim and X. C. Cid, The demographics of physics education research, arXiv:1710.02598.

[68] C. I. Damşa, P. A. Kirschner, J. E. B. Andriessen, G. Erkens, and P. H. M. Sins, Shared epistemic agency: An empirical study of an emergent construct, J. Learn. Sci. 19, 143 (2010).

[69] S. J. Basu, A. C. Barton, N. Clairmont, and D. Locke, Developing a framework for critical science agency through case study in a conceptual physics context, Cultural Studies Sci. Educ. 4, 345 (2008).

[70] A. Godwin, G. Potvin, Z. Hazari, and R. Lock, Identity, critical agency, and engineering: An affective model for 
predicting engineering as a career choice, J. Engin. Educ. 105, 312 (2016).

[71] A. Godwin and G. Potvin, Pushing and pulling Sara: A case study of the contrasting influences of high school and university experiences on engineering agency, identity, and participation, J. Res. Sci. Teach. 54, 439 (2017).
[72] D. Hu and B. M. Zwickl, Examining students' views about validity of experiments: From introductory to Ph.D. students, Phys. Rev. Phys. Educ. Res. 14, 010121 (2018).

[73] S. N. Clarke, I. Howley, L. B. Resnick, and C. P. Rosé, Student agency to participate in dialogic science discussions, Learn. Culture Soc. Interact. 10, 27 (2016). 